\title{
A PHYLOGENETIC INVESTIGATION OF HYDROVATUS, METHLINI AND OTHER PLESIOTYPIC HYDROPORINES (COLEOPTERA: DYTISCIDAE)*
}

\author{
By G. WILliam WolfE \\ Department of Entomology and Economic Zoology, \\ Cook College, New Jersey Agricultural Experiment Station, \\ Rutgers University, New Brunswick, N.J. 08903
}

\section{INTRODUCTION}

Phylogenetic relationships of the Dytiscidae are receiving increased attention (e.g. Burmeister 1976, 1980; Brancucci and Ruhnau 1985, Dettner 1985). This paper is the fifth in a series on primitive hydroporine genera (Wolfe and Matta 1981; Wolfe 1985; Roughley and Wolfe, in press; and Wolfe and Roughley, in press). The first purpose of this paper is to investigate new discoveries concerning the remarkable abdominal structure of methlines and members of Hydrovatus Motschulsky. The peculiar modifications of terminal abdominal terga of members of Hydrovatus and Methlini provide good evidence for monophyly of these taxa. The second purpose is to revise a previous hypothesis (Wolfe 1985) of relationships among plesiotypic hydroporines in light of: 1) the new evidence regarding hydrovatine and methline monophyly, 2) more information on Laccornellus Roughley and Wolfe, 3) different interpretations of some character systems, and 4) computer generated phylogenies.

\section{Materials AND Methods}

Analyzed species are listed in Table 1. Authors of species and genera are listed the first time a name is used in text only if the name is not listed in Table 1 . Table 2 lists characters used in this analysis but see Wolfe (1985) for complete details and illustrations for characters $1-18$.

Dissecting, illustrating, and scanning electron microscope (SEM) techniques are presented in Wolfe (1985). In order to understand the

*Manuscript received by the editor April 20, 1987. 
derivation of the abdominal structure of specimens of Hydrovatini and Methlini, comparisons were made with members of other hydroporine and nonhydroporine genera listed in Table 1.

Relationships between taxa were determined by phylogenetic techniques (essentially Hennigian) that are outlined in Wiley (1980), and Nelson and Platnick (1981). However, phylogenies in the analysis herein were generated and/or analyzed in part with computer programs developed by Dr. D. Swofford (PAUP, Phylogenetic Analysis Using Parsimony, version 2.4).

\section{RESULTS}

\section{Abdominal structure in members of Hydrovatini and Methlini}

Three basic abdominal morphotypes (1-3) are recognized. These three types form a spectrum from the unmodified posteriorly rounded, lightly sclerotized terminal tergum found on members of L. difformis (Figs. 1A-B) (type 1), to intermediate modifications as found in specimens of $H$. pustulatus Melsheimer (type 2) (Figs. 1C-D), to the most derived condition in methlines (type 3) (Figs. 2A-D).

Morphotype 1. (Fig. 1A). In all examined specimens of Canthyporus Zimmermann, Deronectes Sharp, Hydroporus Clairville, Laccornis Gozis, Oreodytes Seidlitz and all nonhydroporines, the posterior edge of the eighth tergum is broadly and evenly convex in dorsal view. The eighth tergite is folded ventrally inward as a ventral flap or fold; this folded portion is hereafter referred to as the ventral fold (Fig. 1B). The ventral fold extends anteriorly for about 25 per cent of the length of the last segment. The outwardly visible posterior edge of tergum- 8 then, is actually the point at which the tergum folds underneath. This character state is clearly evident in many of the abdominal/genitalic illustrations in Burmeister $(1976,1980)$.

Morphotype 2. (Figs. 1C-D). On males and females of Hydrovatus, only the apical tergum is distinctly modified; it is narrow, acutely pointed, and it is differentiated into a dorsal and ventral lamina (Fig. 1C). Neither lamina is distinctly sclerotized, but the ventral lamina is more membranous than the dorsal lamina (Fig. 1D). Dissections were difficult but it appeared that the dorsoapical portion of the ventral lamina possessed a slight inward fold and no ventral fold was evident on the dorsal lamina. 
Table 1. List of species of Dytiscidae examined only for abdominal structure.

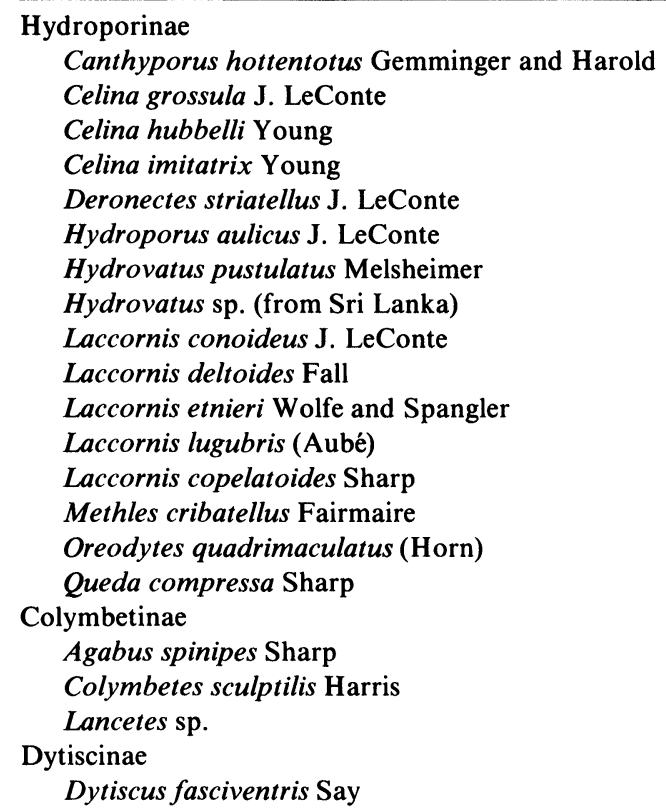

The terminal tergum of specimens of $Q$. compressa Sharp is most similar to morphotype 1 .

Morphotype 3. (Figs. 2A-D). In this morphotype, the seventh and eighth terga are modified in both males and females. Tergum 8 is extremely acutely pointed posteriorly and also consists of a dorsal and ventral lamina. The ventral lamina (Fig. 2B) is a thin, flexible, triangular structure that is similar to that of Hydrovatus; the lateral edges are fringed with setae and curved dorsally thus forming a broad channel into which the dorsal lamina rests.

The dorsal lamina (Fig. 2A) is quite sclerotized, rigid, and overall rather wishbone-shaped. Posteriorly, the structure is somewhat trifid with the medial portion extremely prolonged, laterally compressed, and apically acute; the apicolateral portion is densely setose. Anteriorly, the dorsal lamina extends as a pair of diverging thin apodemes. Each apodeme expands anteriorly into a club shaped apex and extends anteriorly underneath the seventh tergum all the way to the posterior edge of the sixth tergum (Fig. 2D). 

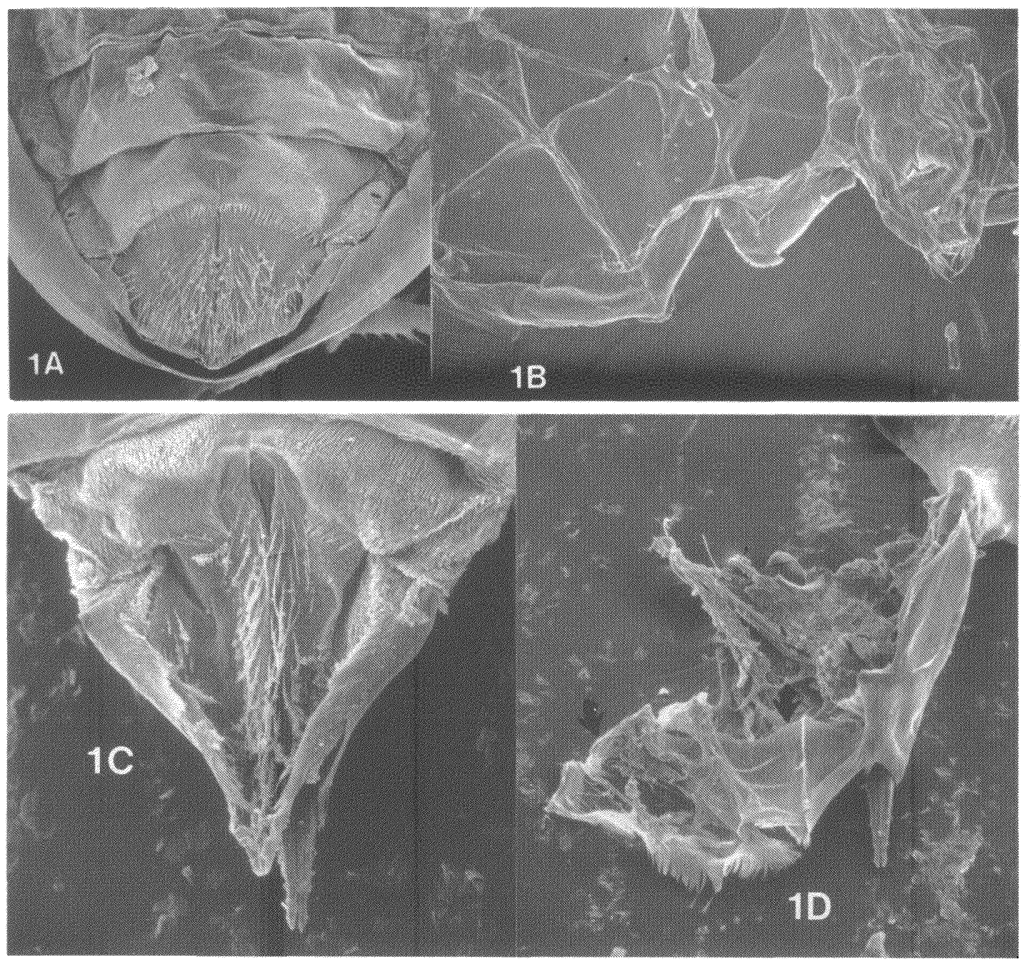

Figure 1. Terminal abdominal structure in Laccornis and Hydrovatus. $\begin{array}{lll}\text { A) Dorsal view of terga 6-8 of Laccornis difformis }(40 \times) & \text { B) Dissected abdominal }\end{array}$ apex of $L$. difformis $(40 \times)$. Tergum 8 is folded back (all the way to the left) so that ventral surface is exposed revealing ventral fold (indicated by arrow); tergum 8 is not bilaminar. C) Acutely pointed eighth tergum of Hydrovatus pustulatus $(80 \times)$. D) Dissected abdominal apex of $\boldsymbol{H}$. pustulatus. Tergum 8 is folded so that dorsal lamina (left arrow) is separated from ventral lamina (right arrow) $(60 \times)$.

The anterior edge of tergum 7 (Fig. 2C) is expanded anteriorly as a broad, bisinuate flange with a short anterolaterally extended apodeme at each anterolateral corner. Apodemes of tergum 7 extend anteriorly for 75 per cent of the length of tergum 6 .

The function of the modified methline abdominal structures has not been observed. Ovipositional function is ruled out because modifications are identical in males and females. Perhaps, the acutely pointed and sclerotized apex is a device for puncturing plant tissue to obtain trapped air. It is interesting that a similar behavior has 


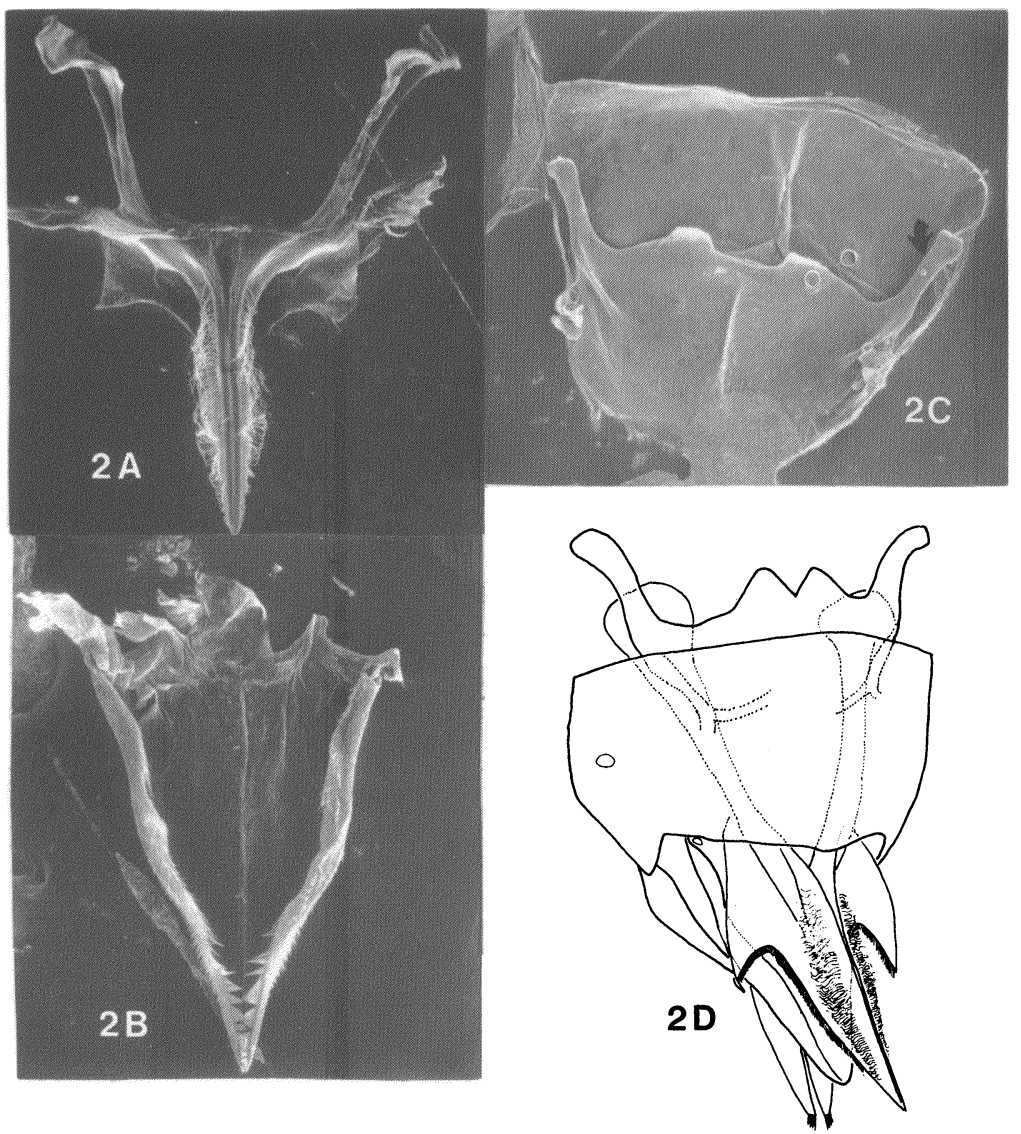

Figure 2. Abdominal structure of C. hubelli $(60 \times)$ A) Acute, pointed, spearshaped dorsal lamina of tergite 8 . B) Ventral lamina. C) Ventral view of terga 6 and 7 showing apodemes on tergum 7 . D) Composite illustration of terga 7 and 8 .

been postulated for larval methlines because of the peculiar posteriorly extended lateral tracheal trunks located at the abdominal apex (Spangler 1973).

\section{Discussion}

Wolfe (1985) presented considerable evidence that Hydroporinae is monophyletic. Among taxa examined (Table 3), Laccornis, Methlini, Hydrovatini, Canthyporus, and Lioporeus were considered the 
most plesiotypic lineages. It also was suggested that: 1) Hydrovatini and Methlini were sister taxa, 2) Bidessini, Oreodytes, and Hygrotus Stephens were relatively more plesiotypic than Hydroporus, Deronectes s.l., Vatellini, and Graptodytes Seidlitz, and 3) L. lugubris and L. copelatoides were related more closely to Canthyporus than to Laccornis.

Since that information was published, several studies have increased significantly our understanding of plesiotypic groups. First, information provided herein more definitely supports monophyly of Hydrovatus and Methlini. Second, Roughley and Wolfe (1987) definitively demonstrated generic status of $L$. copelatoides and $L$. lugubris and assigned those species to a new genus, Laccornellus; evidence supporting a close relationship between Laccornellus and Canthyporus was reviewed. Third, Wolfe and Roughley (in press) completely revised Laccornis and described a new tribe, Laccornini, for the genus.

In light of this new information, the phylogeny of plesiotypic hydroporines proposed by Wolfe (1985) is re-evaluated below. The analysis herein is facilitated by phylogenetic computer programs (PAUP) not previously available to me. I have found that use of these programs supplements interpretation of hypotheses by: 1) more accurately and repeatedly revealing the number of equally parsimonious trees derivable from a character matrix, 2) permitting rapid calculation of consensus trees so that similarities between equally parsimonious trees can be ascertained, 3 ) more definitively allowing assessment of assumptions used in tree construction (e.g. character weighting, character ordering, and addition and elimination of taxa), and 4) allowing easier comparison of trees in terms of homoplasy and tree length.

In summary, it must be stressed that computer generated phylogenies are not intrinsically better than mentally computed trees. However, I think that singular reliance on mental computations can be biased too easily by preconceived notions/hypotheses concerning one or two trees that investigators often have in mind before in depth analyses even begin. Compared to purely mentally constructed hypotheses, computerized constructions (and associated kinds of output) reveal in a more definable and consistent way the frailties of a given hypothesis(es). Although various assumptions/ limitations that are explicitly exposed through computer analysis 
Table 2. Synopsis of plesiotypic and apotypic characters used in analysis. Unless otherwise indicated characters are from the adult stage. See Wolfe (1985) for complete details and illustrations for characters 1-18. Character 19 illustrated herein.

\begin{tabular}{ll}
\hline Character & Plesiotypic state \\
\hline $\begin{array}{ll}\text { 1. Mandibles } \\
\text { 2. Labial spines }\end{array}$ & $\begin{array}{c}\text { ventral medial setae p } \\
\text { in multiple rows, spin } \\
\text { smaller }\end{array}$ \\
$\begin{array}{ll}\text { 3. Larval nasale } \\
\text { absent }\end{array}$ \\
$\begin{array}{ll}\text { 4. Larval galea } & \text { present } \\
\text { 5. Prosternum } & \text { not declivous } \\
\text { 6. Prosternal pore } & \text { absent } \\
\text { 7. Scutellum } & \text { exposed } \\
\text { 8. Elytral ridge } & \text { reduced, not carinate }\end{array}$
\end{tabular}

9. M4 vein

10. Base of metafurca

11. Proventriculus

12. Protarsomere

13. sublateral row of spines of mesotibia

14. Proximity of metafemur to metacoxal process

15. Valvifer

16. Apodeme of genital valves

17. Posterior apex of body

18. Larval urogomphi

19. Posterior tergite contacting oblongulum

not produced and cleft

sclerites of sulci with longitudinal ridge and/or teeth pentamerous

sparser (state 0)

touching to scarcely separated

present

absent

not acuminate

short

not apically acute and bilaminar
Apotypic state

ventral medial setae absent

in single (at most double) row, spines larger

present

1 -without notch

2-with notch

absent (reduced in Methilini)

declivous

present

concealed

present

1-carinate

2-slightly posteriorly elevated

3-distinctly posteriorly elevated

4-ligulate

not contacting oblongulum

produced and dorsally cleft

1 -indistinctly developed

2-distinctly developed

sclerites of sulci with transverse teeth

pseudotetramerous

1 -indistinctly pseudotetramerous

2-distinctly pseudotetramerous

states 1 to 3 , indicate

increasing density

distinctly separated

absent

present

acuminate

long

1-tergum-8 only modified; acute and bilaminar

2-tergum-7 and 8 modified; tergite-8 sclerotized, trifid and spear shaped 
may require that data be much more conservatively interpreted (see below), it no way implies that the only good character data is that data which produces one (or a few) easily interpreted, most parsimonious tree(s). Furthermore, many assumptions (e.g., characterweighting, assumed monophyly of subgroups, occurrence of equally parsimonious trees) that require explicit enumeration with a computerized approach are used implicitly (sometimes ignored) in mentally produced hypotheses.

\section{Hydrovatini-Methlini monophyly}

Polarizing the character states of members of Hydrovatus and Methlini is rather straight forward. Morphotype-1 occurs in members of Hydroporus, Deronectes, Oreodytes, Canthyporus, Laccornis, and all non-hydroporines (see Table 1). It is logical to postulate a morphocline that proceeds from morphotype-1, through morphotype- 2 and culminating in morphotype- 3 . Thus the structural modifications of morphotype-2 are a synapotypy unifying Hydrovatus and Methlini and the apotypic modifications associated with morphotype-3 phylogenetically cluster Methles and Celina. These latter facts help offset the conflict created by the exposed scutellum in members of Celina and concealed condition in Methles.

There are potential synapotypies for Queda and Hydrovatus: the prosternal process is extremely broad, the metafurca is reduced in size and wishbone shaped, an elytral humeral carina is present, and the internal elytral ridge is expanded throughout its length in members of both genera. However, I had hoped that the unification of Queda and Hydrovatus in Hydrovatini (Zimmerman 1920) could be supported further through this analysis; unfortunately this is not the case. As stated above, abdominal modifications are plesiotypic in members of Queda, so much so that inclusion in Hydrovatini based on the structure of tergum 8 is not obvious. Furthermore, the metafemoral apices are distinctly separate from the metacoxal lobes in members of Queda (apotypic) while in Hydrovatus and methlines the metafemora almost attain or do reach the metacoxal lobes (plesiotypic). In summary, recent studies are making the phylogenetic relationship of Queda more enigmatic rather than more understandable and this genus requires further study.

\section{Phylogenetic re-evaluation of plesiotypic Hydroporines}

The analysis below is based on a modified version (Table 3 herein) of the character state matrix of Wolfe (1985, Table 2, pp. 136-137). 
Previously there were tabular errors associated with two characters. Character-2 (arrangement of labial spines) for members of Q. compressa should have read 0 , not 1 . For character-14, I intended proximity of the metafemoral base to the metacoxal lobes to be coded dichotomously; therefore, each 2 in that column should have been 1 and the 1 recorded for specimens of $L$. lugubris and $L$. copelatoides should have been 0 . These were tabular errors only and were not incorporated into the phylogeny proposed by Wolfe (1985). It was indicated that medial mandibular setae were absent in all hydroporines; however, there is a reduced row on specimens of $M$. mexicanus Sharp and $O$. rivalis (Gyllenhal) that is difficult to see; therefore, character 1 should have read 0 , not 1 , for these two species. The discovery of medial mandibular setae in M. mexicanus and $O$. rivalis did not alter their phylogenetic placement; these two taxa still are regarded as rather apotypic.

Previously, I was not sure about the status or placement of $L$. lugubris and L. copelatoides. However, further study (Roughley and Wolfe, 1987) adequately demonstrated that those species formed a distinct unit and they were assigned to a new genus, Laccornellus, and Laccornellus is included in the analysis below.

Before analysis with PAUP was conducted, groups of identical taxa were identified and each group was represented by one species. With these modifications, computer analysis revealed more than 100 equally parsimonious trees: however, it is interesting to note that a consensus tree of these first 100 trees showed the same basic patterns as previously proposed in Wolfe (1985).

To reduce the number of equally parsimonious trees below 100, I represented several groups considered to be monophyletic by one species. L. triangularis (Fall) was used for Lioporeus, L. kocai (Ganglebauer) for Laccornis, U. lacustris (Say) for Bidessini, and M. cribatellus Fairmaire for the clade that includes Methlini and Hydrovatini. Justification for monophyly of Lioporeus and Laccornis is based on information in Wolfe and Matta (1981) and Wolfe and Roughley (in press) respectively. Bidessini is considered monophyletic based on metacoxal process structure. Justification for monophyly of Methlini and Hydrovatini is not conclusive, as long as Queda is included in Hydrovatini; however, until more characters are discovered to clarify the phylogenetic position of the enigmatic Queda, I assume it shares a most recent common ancestor with Hydrovatus and that the distinct gap between metafemora and 


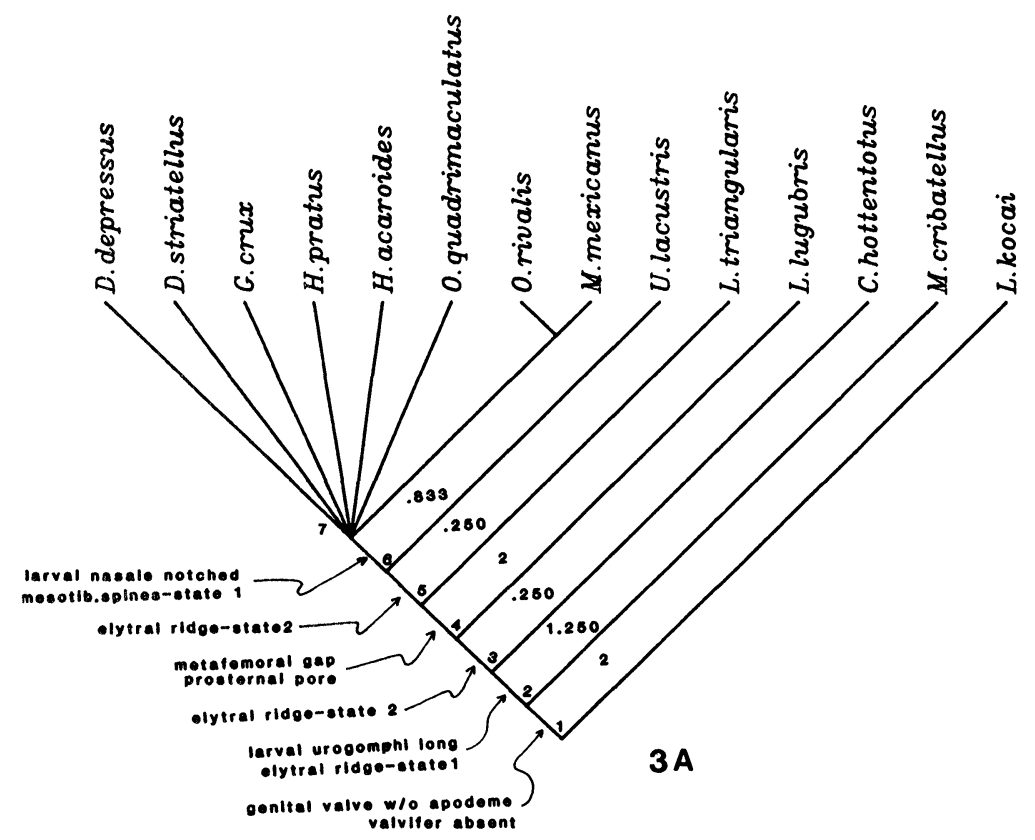

Figure 3, above and opposite. Phylogenies discussed in text. A) Consensus tree produced from 99 equally parsimonious trees after all characters were scaled. Species names are used for taxa actually used in analysis. Numbers 1-7 are node numbers; numbers $.250, .833$, etc. are branch lengths for each proximate HTU. The indicated character state changes are derived directly from computer analysis and are interpreted/evaluated in text. B) and C) More conservative phylogenetic hypotheses. See text for discussion. Generic and tribal names are used in place of species names.

metacoxal lobes is secondarily derived in members of $Q$. compressa.

Even with the above specified reduction in species number, more than 100 equally parsimonious trees still are produced. Rather than immediately further decrease the number of species, I next elected to scale all characters; scaling is useful because it equalizes the influence of 2-state and multi-state characters by decreasing weights of character states of multi-state characters so that character states of all characters are on an interval from 0 to 1 . For example, a 3-state character would be coded 0-.5-1 instead of 0-1-2 and a 4-state character recoded 0-.333-.666-1 (see Swofford 1985). With all characters scaled, 99 equally parsimonious trees are produced. The consensus tree (Fig. 3A) continues to show the same basic set of relationship proposed in Wolfe (1985). 


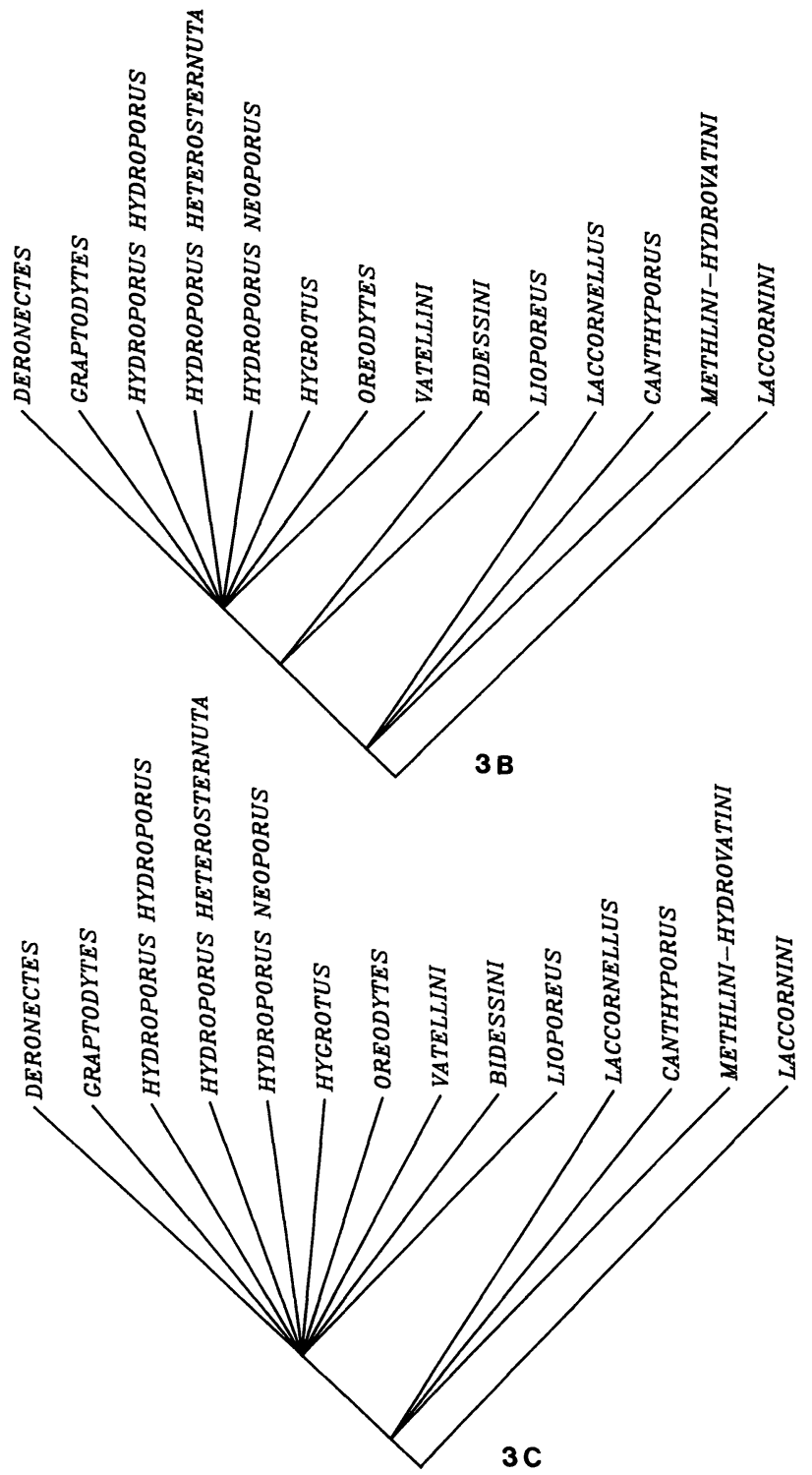


Table 3. Character states used in phylogenetic analysis (modified from Wolfe [1985]). See Table 2 for character description.

\begin{tabular}{llllllllllllllllllll}
\hline$\quad$ Character No. & 1 & 2 & 3 & 4 & 5 & 6 & 7 & 8 & 9 & 10 & 11 & 12 & 13 & 14 & 15 & 16 & 17 & 18 & 19 \\
\hline $\begin{array}{l}\text { Colymbetinae (out-group) } \\
\quad \begin{array}{l}\text { Matus ovatus* } \\
\text { Hydroporinae }\end{array}\end{array}$ & 0 & 0 & 0 & 0 & 0 & 0 & 0 & 0 & 0 & 0 & 0 & 0 & 0 & 0 & 0 & 0 & 0 & 0 & 0 \\
Methlini & & & & & & & & & & & & & & & & & & & \\
$\quad \begin{array}{l}\text { Methles cribatellus } \\
\text { Celina hubbelli }\end{array}$ & 1 & 1 & 1 & 1 & 1 & 0 & 1 & 0 & 1 & 1 & 1 & 1 & 0 & 0 & 1 & 1 & 1 & 0 & 2 \\
C. imitatrix & 1 & 1 & 1 & 1 & 1 & 0 & 0 & 0 & 1 & 1 & 1 & 2 & 0 & 0 & 1 & 1 & 1 & 0 & 2 \\
C. grossula & 1 & 1 & 1 & 1 & 1 & 0 & 0 & 0 & 1 & 1 & 1 & 2 & 1 & 0 & 1 & 1 & 1 & 0 & 2 \\
& 1 & 1 & 1 & 1 & 1 & 0 & 0 & 0 & 1 & 1 & 1 & 2 & 1 & 0 & 1 & 1 & 1 & 0 & 2
\end{tabular}

Hydrovatini

Hydrovatus pustulatus $\quad \begin{array}{llllllllllllllllllll} & 1 & 1 & 1 & 1 & 1 & 0 & 1 & 3 & 1 & 2 & 1 & 2 & 1 & 0 & 1 & 1 & 1 & 0 & 1\end{array}$

$\begin{array}{lllllllllllllllllllll}\text { Queda compressa } & 1 & 0 & \text { ? } & \text { ? } & 1 & 0 & 1 & 3 & 1 & 0 & 1 & 2 & 1 & 1 & 1 & 1 & 1 & \text { ? } & 0\end{array}$

Bidessini

Uvarus lacustris

Bidessonotus

inconspiciuus

Hydroporini sensu latu

Laccornis kocae

L. conoideus

L. etneiri

L. deltoides

Laccornellus copelatoides

L. lugubris

Canthyporus

hottentotus

Lioporeus pilatei

L. triangularis

$\begin{array}{lllllllllllllllllll}1 & 1 & 1 & 1 & 1 & 1 & 1 & 3 & 1 & 2 & 1 & 2 & 0 & 1 & 1 & 1 & 0 & 1 & 0\end{array}$

Hygrotus acaroides

H. nubilis

Oreodytes

quadrimaculatus

O. rivalis

O. snoqualmie

Graptodytes crux

Deronectes depressus

D. striatellus

Hydroporus (Hydroporus rufilabris

$\begin{array}{lllllllllllllllllll}1 & 1 & ? & ? & 1 & 1 & 1 & 4 & 1 & 2 & 1 & 1 & 0 & 1 & 1 & 1 & 0 & ? & 0\end{array}$

$\begin{array}{lllllllllllllllllll}1 & 1 & 1 & 1 & 1 & 0 & 1 & 0 & 1 & 2 & 1 & 2 & 0 & 0 & 0 & 0 & 0 & 0 & 0\end{array}$

$\begin{array}{lllllllllllllllllll}1 & 1 & 1 & 1 & 1 & 0 & 1 & 0 & 1 & 2 & 1 & 2 & 1 & 0 & 0 & 0 & 0 & 0 & 0\end{array}$

$\begin{array}{lllllllllllllllllll}1 & 1 & 1 & 1 & 1 & 1 & 1 & 0 & 1 & 2 & 1 & 2 & 1 & 0 & 0 & 0 & 0 & 0 & 0\end{array}$

$\begin{array}{lllllllllllllllllll}1 & 1 & 1 & 1 & 1 & 1 & 1 & 1 & 1 & 2 & 1 & 2 & 1 & 0 & 0 & 0 & 0 & 0 & 0\end{array}$

H. (Neoporus) clypealis

$H$. (N) undulatus

$\begin{array}{lllllllllllllllllll}1 & 1 & ? & ? & 1 & 0 & 1 & 2 & 1 & 2 & 1 & 2 & 0 & 0 & 1 & 1 & 0 & ? & 0\end{array}$

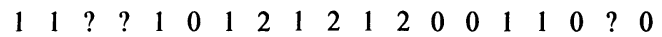

$\begin{array}{lllllllllllllllllll}1 & 1 & 1 & 1 & 1 & 0 & 1 & 1 & 1 & 2 & 1 & 2 & 0 & 0 & 1 & 1 & 0 & 0 & 0\end{array}$

$\begin{array}{lllllllllllllllllll}1 & 1 & ? & ? & 1 & 1 & 1 & 1 & 1 & 2 & 1 & 2 & 0 & 1 & 1 & 1 & 0 & ? & 0\end{array}$

$\begin{array}{lllllllllllllllllll}1 & 1 & ? & ? & 1 & 1 & 1 & 1 & 1 & 2 & 1 & 1 & 0 & 1 & 1 & 1 & 0 & ? & 0\end{array}$

$\begin{array}{lllllllllllllllllll}1 & 1 & 2 & 1 & 1 & 1 & 1 & 4 & 1 & 2 & 1 & 2 & 1 & 1 & 1 & 1 & 0 & 1 & 0\end{array}$

$\begin{array}{lllllllllllllllllll}1 & 1 & 2 & 1 & 1 & 1 & 1 & 4 & 1 & 2 & 1 & 2 & 1 & 1 & 1 & 1 & 0 & 1 & 0\end{array}$

$\begin{array}{lllllllllllllllllll}1 & 1 & ? & 1 & 1 & 1 & 1 & 3 & 1 & 2 & 1 & 2 & 3 & 1 & 1 & 1 & 0 & 1 & 0\end{array}$

$\begin{array}{lllllllllllllllllll}0 & 1 & ? & 1 & 1 & 1 & 1 & 2 & 1 & 2 & 1 & 2 & 1 & 1 & 1 & 1 & 0 & 1 & 0\end{array}$

$\begin{array}{lllllllllllllllllll}1 & 1 & ? & 1 & 1 & 1 & 1 & 2 & 1 & 2 & 1 & 2 & 1 & 1 & 1 & 1 & 0 & 1 & 0\end{array}$

$\begin{array}{lllllllllllllllllll}1 & 1 & 2 & 1 & 1 & 1 & 1 & 3 & 1 & 2 & 1 & 2 & 3 & 1 & 1 & 1 & 0 & 1 & 0\end{array}$

$\begin{array}{lllllllllllllllllll}1 & 1 & 2 & 1 & 1 & 1 & 1 & 3 & 1 & 2 & 1 & 2 & 1 & 1 & 1 & 1 & 0 & 1 & 0\end{array}$

$\begin{array}{lllllllllllllllllll}1 & 1 & 2 & 1 & 1 & 1 & 1 & 2 & 1 & 2 & 1 & 2 & 3 & 1 & 1 & 1 & 0 & 1 & 0\end{array}$

$\begin{array}{lllllllllllllllllll}1 & 1 & 2 & 1 & 1 & 1 & 1 & 2 & 1 & 2 & 1 & 2 & 3 & 1 & 1 & 1 & 0 & 1 & 0\end{array}$

$\begin{array}{lllllllllllllllllll}1 & 1 & 2 & 1 & 1 & 1 & 1 & 3 & 1 & 2 & 1 & 2 & 3 & 1 & 1 & 1 & 0 & 1 & 0\end{array}$

$\begin{array}{lllllllllllllllllll}1 & 1 & 2 & 1 & 1 & 1 & 1 & 3 & 1 & 2 & 1 & 2 & 3 & 1 & 1 & 1 & 0 & 1 & 0\end{array}$ 
Table 3. continued

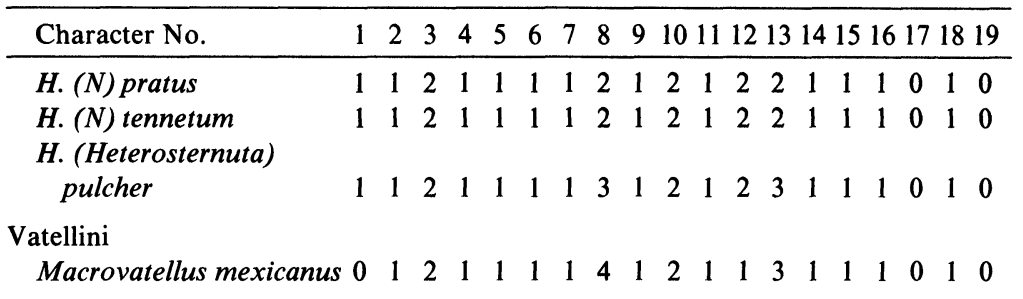

The number of equally parsimonious trees can be reduced more by eliminating more species. For example, if $O$. quadrimaculatus (Horn) is removed and characters still are scaled, 27 equally parsimonious trees are produced. It is interesting that except for the omission of $O$. quadrimaculatus, the consensus tree of those 27 trees remains identical to that shown in Fig. 3A.

As indicated previously, it is obvious that there are not enough characters to resolve the phylogenetic relationship of all taxa listed in Table 3. Phylogenetic problems seem particularly acute in "higher" hydroporines (Deronectes, Hydroporus, etc). This is borne out by the fact that eliminating taxa from among more apotypic groups (e.g. O. quadrimaculatus) significantly decreases the number of equally parsimonious trees (from over 100 to 99 to 27) without affecting relationship among plesiotypic clades. Even treating all characters as unordered did not perturb relationship among primitive groups.

Despite apparent stability of relationship among primitive groups, there still are only a few synapotypies to support proposed relationships and not all synapotypies are equally important, especially after decreasing weight of some characters by scaling. Weaknesses and strengths of various parts of the phylogenetic hypothesis in Fig. 3A overall are reflected by computed branch lengths (length = number of character state changes or synapotypies per line segment), after Laccornellus is added to the analysis and characters are scaled. For example the lengths of the branches connecting node three to node four and from node five to node six is only 0.250 for each. The length of the branch connecting node six to node seven is 0.833 . These problems are elaborated further below. 
Evaluation of synapotypies

All trees show Laccornis as the most primitive clade followed by successive divergence of Methles, Canthyporus, Laccornellus, Lioporeus, Uvarus Guignot, and finally a large polychotomy containing Hydroporus s.l., Deronectes, Oreodytes, Hygrotus, Macrovatellus Sharp, and Graptodytes. Oreodytes rivalis is shown as the sister taxon to $M$. mexicanus; however, this sister group relationship was based on a character loss (loss of mandibular setation) and I feel confident future studies will not support this close relationship between $M$. mexicanus and $O$. rivalis. Relationships among Deronectes, Oreodytes, etc. are not known and obviously require considerably more study.

The primary character involved in arraying the more primitive lineages is development of the elytral ridge which is homoplasious (consistency index $[\mathrm{CI}]=.444$ ). Characters that are homoplasious can be phylogenetically useful, but only if polarities for the character states are worked out more comprehensively at and below the generic level so that the plesiotypic states can reasonably be predicted for each genus; unfortunately, this kind of meticulous work is only finished for Lioporeus, Laccornis and Laccornellus. While I am confident that the trend for the internal elytral ridge is generally from the non-ridged condition to the more ligulate state, I am not sure of the exact plesiotypic condition for all genera analyzed; therefore, excessive reliance on this character is not justified.

Relationships among the plesiotypic groups also are in part established by nasale structure and length of the larval urogomphus. Larval characters often are rather conservative and therefore useful for higher level phylogenetic analysis. However, no larvae are described for any members of two critical genera, Lioporeus and Laccornellus. Furthermore, Watts (1970) demonstrated considerable variation in length of larval urogomphus in members of Hygrotus. Also, character states for urogomphal length and lateral notch of the nasale are not clearly dichotomous. For these reasons, decreased reliance on these characters is appropriate.

The most reliable characters available are presence/absence of a valvifer, presence/absence of the prosternal pore, and degree of separation of base of the metafemora and metacoxal lobes. Within the Hydroporinae, the prosternal pore has evolved at least twice, once in Laccornis and then in taxa above node 4. Wolfe and Rough- 
ley (in press) clearly showed that the pore is secondarily derived in Laccornis. Although this character needs to be analyzed in more taxa, among species examined, it is dichotomous and appears to be a reliable phylogenetic indicator.

In all examined members of Laccornis, Methlini, Hydrovatus, Laccornellus, and Canthyporus, metafemora touch or almost touch the metacoxal lobes. All taxa beyond node 4 have a distinct gap between the metafemoral base and metacoxal lobes. I think that this character is important; however, as long as Queda is retained in Hydrovatini the presence of the metafemoral gap will be homoplasious in Hydroporinae.

Presence of a valvifer in members of Laccornis indicates a plesiotypic position for that genus (Burmeister 1976, Wolfe 1985). This is an internal character that is part of a complex muscular/structural system (see Burmeister 1976) and I consider it very significant. Furthermore, according to the phylogeny (Fig. 3A) this character is perfectly consistent.

One important final point is that if historical zoogeographic implications previously proposed concerning Northern and Southern hemisphere taxa (Wolfe 1985) are correct, increased homoplasy in all characters will have to be accepted. Synapotypies associated even with valvifer, metacoxae and prosternal pore may have evolved twice: once in northern hemisphere hydroporines and once in hydroporines of the southern hemisphere (see Wolfe 1985 for more complete discussion).

Conclusions. Information provided herein substantiates the hypothesis that Hydrovatus and Methlini are sister taxa; however, inclusion of Queda in Hydrovatini is questioned and requires further study.

The overall phylogenetic hypothesis proposed in Wolfe (1985) is overextended. After re-interpretation of specified characters, phylogenetic analysis facilitated by PAUP reveals well over 100 equally parsimonious trees. By using one representative species for each of Bidessini, Lioporeus, Laccornis, and Methlini/Hydrovatini, and scaling all characters, 99 equally parsimonious trees were produced; the consensus tree of the 99 equally parsimonious trees very closely approximates the tree in Fig. 45 of Wolfe (1985). However, reevaluation of synapotypies between nodes 1-4 in Fig. 3A herein suggests that relationships between Laccornellus, Canthyporus, and 
Methylini-Hydrovatini cannot be conclusively resolved and the phylogeny in Wolfe (1985) should be adjusted. At best (Fig. 3B), structural data indicates Laccornis is the most plesiotypic clade followed by a polychotomy that includes Laccornellus, Canthyporus, and Methlini-Hydrovatini. Most characters indicate Bidessini and Lioporeus are more plesiotypic than remaining hydroporines. However, the primary characters suggesting this are either variable or gradational; although character trends are evident it is difficult to polarize these characters (e.g. internal elytral ridge, mesotibial spines) on a node by node basis.

It seems that the best hypothesis for now is that of Fig. 3C, at least until immature stages of Lioporeus and Laccornellus are described and/or more synapotypies are discovered. For example, if members of Lioporeus, Laccornellus, and/or all had distinctly long urogomphi, I would be more confident about using that character as a synapotypy to separate Canthyporus etc. from MethliniHydrovatini-Laccornini. Further resolution of phylogeny of hydroporines will require analyses emphasizing more African and Australian genera so that an alternate hypothesis involving independent evolution of the northern and southern hemisphere hydroporine faunas can be investigated adequately.

\section{SUMMARY}

The eighth abdominal tergum of most hydroporines is evenly convex posteriorly and ventrally is folded inward for about 0.25 the length of the tergum. On males and females of Hydrovatus and Methlini (Celina and Methles), tergum 8 is posteriorly acute and consists of a dorsal and ventral lamina that are about equal in size. In methlines, terga 7 and 8 are modified. On tergum 8 , the dorsal lamina additionally is modified posteriorly into a distinct, trifid, highly sclerotized, spearlike structure with two long, diverging, anteriorly extended apodemes. Shorter anteriorly extended apodemes also are present on the anterior edge of tergum 7. These modifications suggest that Hydrovatus and Methlini form a monophyletic unit and also support the contention that Methlini (which includes Celina and Methles) is monophyletic. Specimens of Queda compressa do not possess these distinctive abdominal modifications and that genus may be improperly assigned to Hydrovatini. 
Relationships among Laccornis, Methlini-Hydrovatus, Canthyporus, Laccornellus, and Lioporeus proposed by Wolfe (1985) are reviewed. Based on structural considerations only, Laccornis still is recognized as the sister to all other Hydroporinae, and the next most plesiotypic group is represented by a polychotomy of Canthyporus, Laccornellus, and Methilini-Hydrovatus; however, the specific relationships between the latter three clades cannot be as confidently predicted as previously thought. Members of Lioporeous, Bidessini, Deronectes, Oreodytes, Hygrotus, Graptodytes, and Hydroporus sensu latu are relatively more apotypic than Canthyporus etc. Characteristics of the internal elytral ridge and mesotibial chaetotaxy suggest Lioporeus and Bidessini are more primitive than the latter five groups, but these latter relationships cannot be established conclusively.

\section{ACKNOWLEDGMENTS}

I thank Dr. R. E. Roughley (University of Manitoba) for many hours of discussions and debate concerning dytiscid phylogeny; Dr. P. J. Spangler (National Museum of Natural History), Dr. D. Kavanaugh (California Academy of Science), C. H. S. Watts (South Australian Museum), and M. Bacchus (British Museum Natural History) for providing specimens critical to this study and Ms. Sule Oygur for assistance in manuscript preparation.

This article is New Jersey Agricultural Experiment Station Publication No. D-08412-06-87, supported by state funds.

\section{Literature Cited}

Brancucci, M. and S. Ruhnau. 1985. Studies on the genus Lancetes. 1. Additional notes on Lancetes angusticollis (Curtis) and description of the pupa (Coleoptera: Dytiscidae). in: G. W. Wolfe and R. E. Roughley eds. Proceedings of the First International Conference on Classification, Phylogeny, and Natural History of Hydradephaga. Proceedings of the Academy of Natural Sciences of Philadelphia 137: 46-52.

Burmeister, E. 1976. Der Ovipositor der Hydradephaga (Coleoptera) und seine phylogenetische Bedentung unter besondesen Berucksichtigung der Dytiscidae. Zoomorphologie 85: 165-257.

Burmeister, E. 1980. Funktionsmorphologie and Evolution des Ovipositor der Adephaga (Coleoptera). Verh. naturwiss. Ver. Hamburg (NF) 24(1): 89-184.

DetTNER, K. 1985. Ecological and phylogenetic significance of defensive compounds from pygidial glands of Hydroporinae (Coleoptera). in G. W. Wolfe and 
R. E. Roughley eds. Proceedings of the First International Conference on Classification, Phylogeny, and Natural History of Hydradephaga. Proceedings of the Academy of Natural Sciences of Philadelphia 137: 156-171.

Nelson, G. ANd N. Platnick. 1981. Systematics and Biogeography Cladistics and Vicariance. Columbia University Press, New York.

Roughley, R. E. AND G. W. Wolfe. 1987. Laccornellus (Coleoptera: Dytiscidae), a new hydroporine genus from austral South America. Canadian Journal of Zoology 65(6): 1346-1353.

Spangler, P. J. 1973. A description of the larva of Celina angustata Aubé (Coleoptera: Dytiscidae). Journal of the Washington Academy of Science. 63: 165-168.

Swofford, D. L. 1985. PAUP Phylogenetic Analysis Using Parsimony Version 2.4. Privately Published.

WatTs, C. H. S. 1970. The larvae of some Dytiscidae (Coleoptera) from Delta, Manitoba. The Canadian Entomologist. 102(6): 716-728.

Wiley, E. D. 1981. Phylogenetics, The Theory and Practice of Phylogenetic Systematics. John Wiley and Sons. New York.

Wolfe, G. W. AND J. F. Matta. 1981. Notes on nomenclature and classification of Hydroporus subgenera with the description of a new genus of Hydroporini (Coleoptera: Dytiscidae). Pan-Pacific Entomologist 57(1): 145-175.

WOLFE, G. W. 1985. A phylogenetic analysis of plesiotypic hydroporine lineages with an emphasis on Laccornis Des Gozis (Coleoptera: Dytiscidae). in: G. W. Wolfe and R. E. Roughley eds. Proceedings of the First International Conference on Classification, Phylogeny, and Natural History of Hydradephaga. Proceedings of the Academy of Natural Sciences of Philadelphia 137: 132-155.

Wolfe, G. W. AND R. E. Roughley. A taxonomic, phylogenetic, and zoogeographic analysis of Laccornis Gozis (Coleoptera: Dytiscidae) with the description of a new tribe of Hydroporinae. Submitted.

Zimmermann, A. 1920. Coleopterorum Catalogus. Pars 71: Dytiscidae, Haliplidae, Hygrobriidae, Amphizoidae. W. Junk, Berlin. 

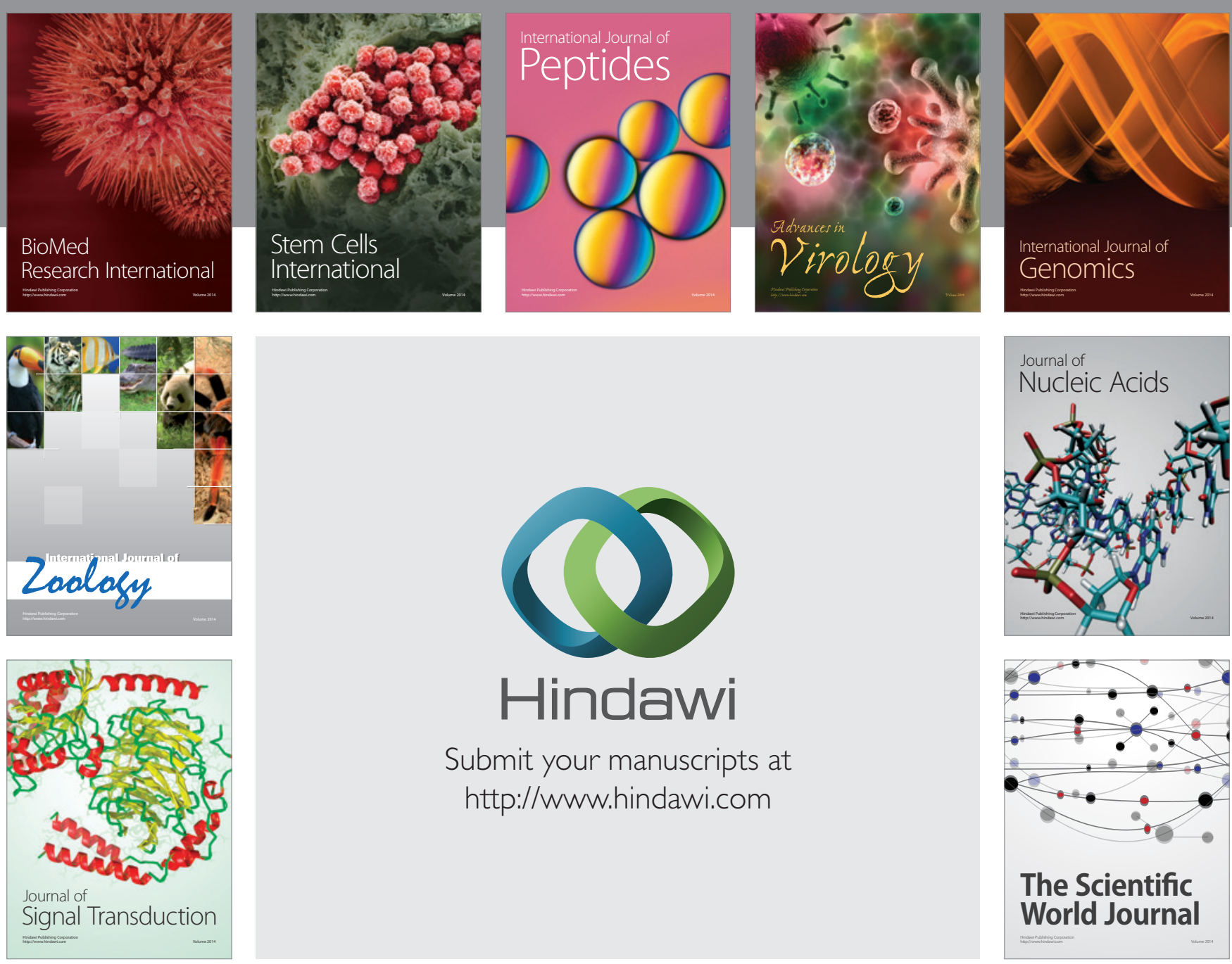

Submit your manuscripts at

http://www.hindawi.com
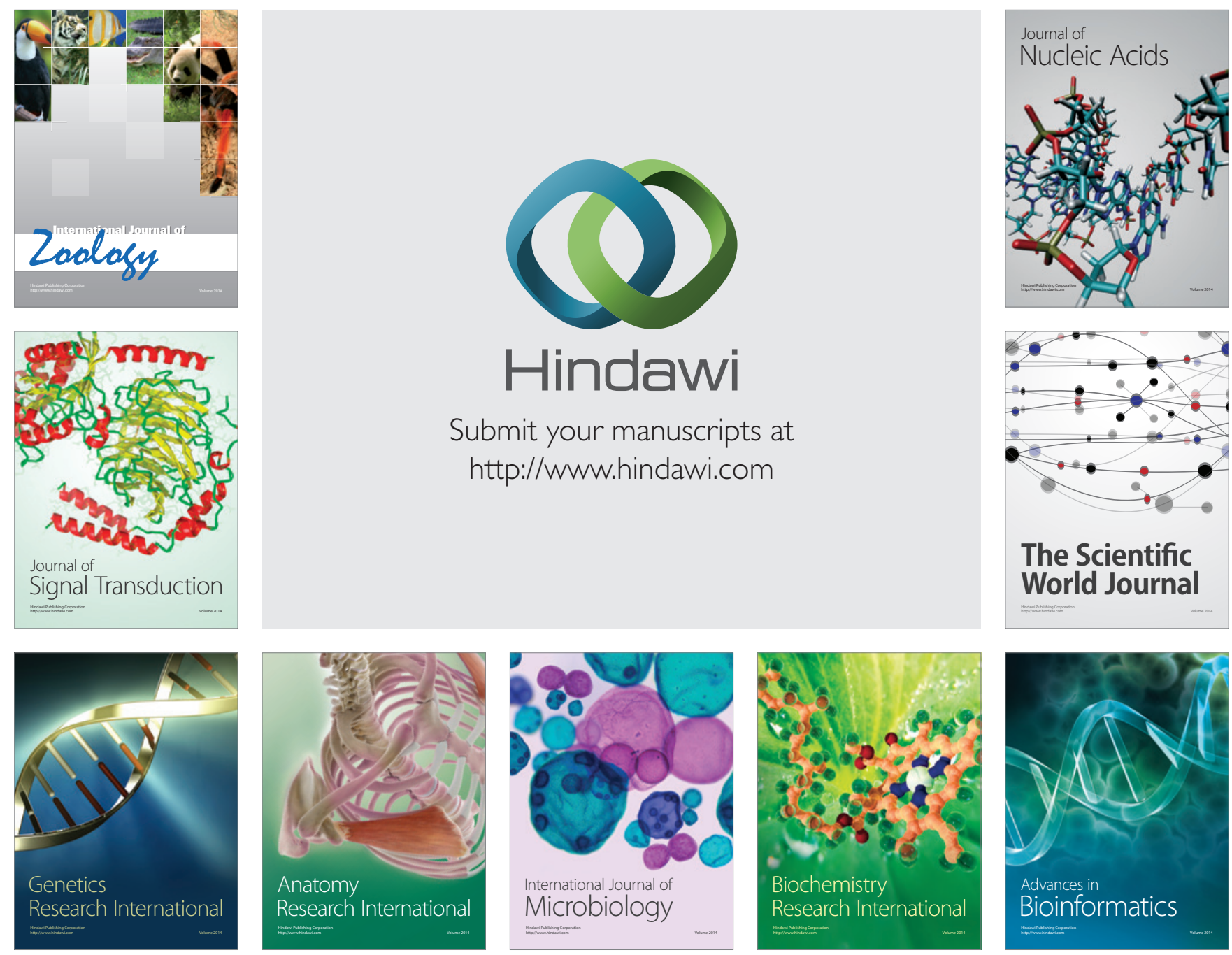

The Scientific World Journal
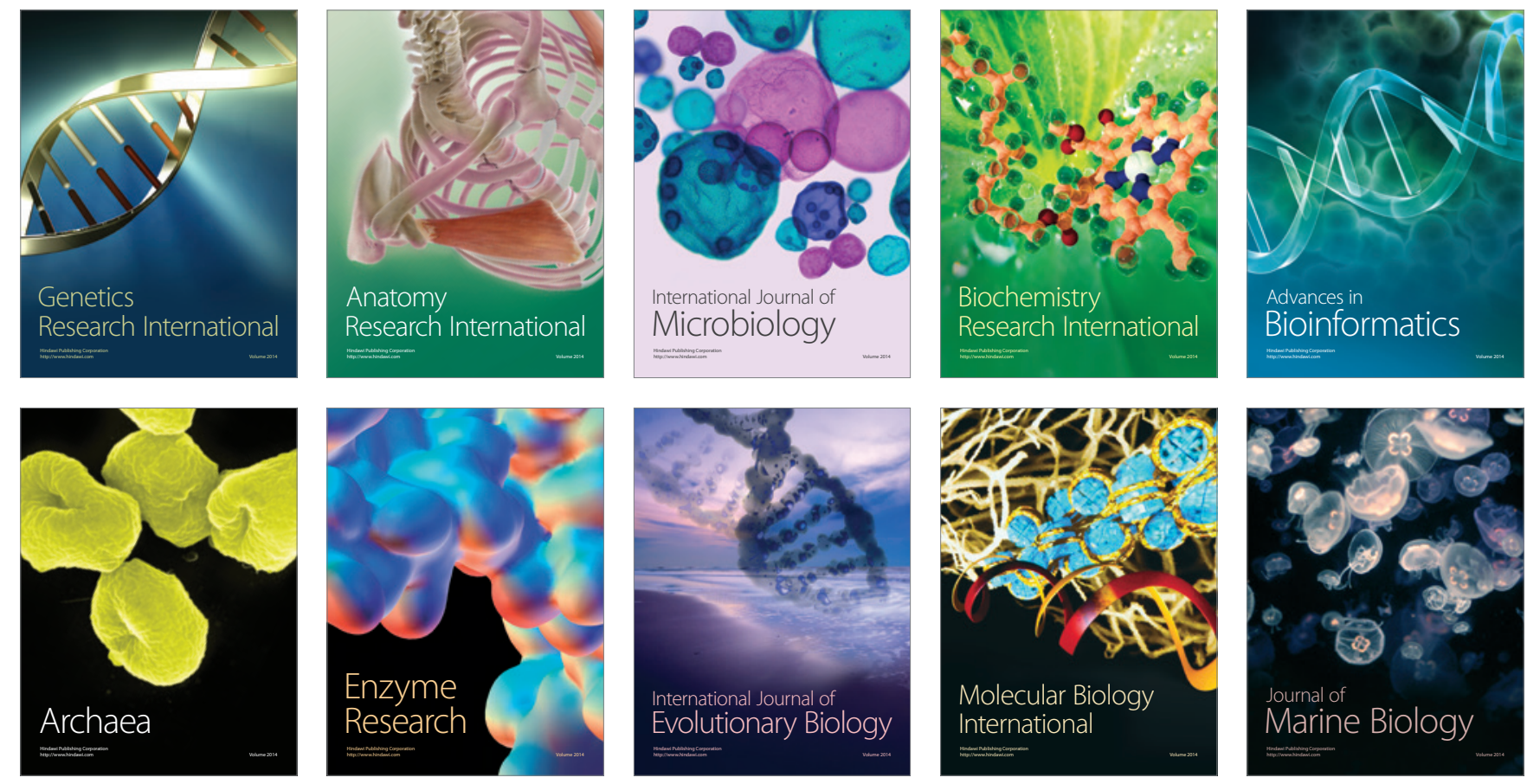